\title{
The Realms Of Knowledge Management From An Organizational Perspective
}

M. Abu Zar Wajidi, University of Karachi, Pakistan

Muhammad Asim, University of Karachi, Pakistan

\begin{abstract}
The international scenario of industrial competitiveness has tremendously transformed during the last few decades. Organizations competing in the global economy are facing different challenges in order to survive and make progress. The rapid advancements in computer technology, emergence of the internet, World Wide Web, and telecommunication devices have profoundly affected the activities of business organizations. These trends have forced the organizations to reshape and redefine their economic and business strategies. This factor can be counted as the knowledge boom which, in today's developed world, is more appropriately referred to as the knowledge management. Knowledge Management is one of the burning topics nowadays, which has brought significant changes in organizations in developed countries and gave new impetus for global competition and new challenges for the organization in developing countries. This paper aims at providing a ground work for organizations in developing countries. It will help organizations provide a framework for contribution to knowledge management aspect and also enable organizations in developing countries, especially large organizations intending to globalize their operations, to analyze their position and design a future strategy accordingly.
\end{abstract}

Keywords: ICT, KM, Tacit Knowledge, Explicit Knowledge, Knowledge Mapping, Group Support System.

\section{INTRODUCTION}

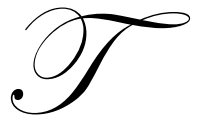

he knowledge-related activities are important for the economic development of a country; knowledge is imparted by the universities, processed by the organizations, and used by the society. Knowledge itself produces nothing unless it is processed into an operation. The need is to utilize the knowledge so as to accelerate the economic growth, develop meaningful relation with the industry, and finds new technologies by creating new ideas and formulating new theories and procedures. All of those are the critical elements of knowledge-creating activities. How knowledge-based innovation can be used in modernizing Pakistan's industrial and business structure is the critical question? Modernization cannot lead without knowledge that developed society has already built. An urge for modern management will convert knowledge from social ornament and luxury into the true capital of any economy. Knowledge entails vibrant modification at the broader level of technology, science and education policies.

The last decade of the 20th century experienced cataclysmic changes in organizations' structure and performance, although there are several themes that brought changes in culture, design and environment of contemporary organizations all over the world namely globalization, interdependence and free markets economy which forced the organizations to reshape their business strategies. However, one factor alone has altered the very nature of the organizations referred to as the knowledge boom, which gave birth to the new economy in which brain power has become a more critical resource than the machine power.

The modern development, especially in the communication sector, is noteworthy, which brought the world closer to the extent that it can be more appropriately referred to as the global village. The microelectronic advancements have revolutionized the life, and so organizations are also under this influence. These global developments also affected Pakistan's business environment and several applications of information and communication technology (ICT) have gained considerable popularity as instruments for knowledge management. 
The introduction of specific ICT applications (Internet, Intranet groupware, etc.) and their friendly user attitude with less cost had facilitated convenient ways to substitute traditional office management.

It is interesting and appreciating to note that Pakistan's policies have been consistent for the last five years, which resulted in attracting foreign investors, and no doubt Pakistan's industrial growth rate and manufacturing sectors indicate positive signs during the last five years. Pakistan's economy is growing, but it still has to do a lot to compete with the developed world. The best way to compete is to bring change in the mindset, in organizational design, cultures and operations. These changes can come through the knowledge creation, acquisition and absorption. Hopefully organizations in Pakistan are now realizing this fact that competitive edge can be gained only this way, thus firms are increasingly becoming players in a hyper-competitive game and engaging in extensive knowledge sourcing from all sorts of knowledge producers - whether they be suppliers, customers and clients, universities or employees controlling critical knowledge to support the knowledge-based strategies that are appropriate for the new competitive era.

\section{WHAT IS KNOWLEDGE MANAGEMENT}

Knowledge Management has been around for a few years now, but for many people, it still remains undefined. The recent re-emergence of the term has a lot to do with the progress of technology, which has provided new tools with which use and share knowledge within organizations.

Before proceeding to the definition of knowledge management, it is necessary to define knowledge. Data, in an organization, reveals results and facts. Relations existing between data and other relations are capable to represent such data in the form of organized information. Patterns of relations of data and information and other patterns have the capacity to represent knowledge (see Figure 1- Source: Information Management and Economics, Inc.,http://home.istar.ca/ ime/knowledge.htm). A representation is only useful and of advantage when it is comprehensible, and after such quality of comprehension, the representation is termed as knowledge for those who can understand it.

Data $\underset{\text { Relations }}{\stackrel{\text { Understanding }}{\longrightarrow} \text { Information } \underset{\text { Patterns }}{\longrightarrow} \longrightarrow \begin{array}{c}\text { Understanding } \\ \text { Knowledge } \\ \text { Principles }\end{array}} \longrightarrow$ Value

Figure 1

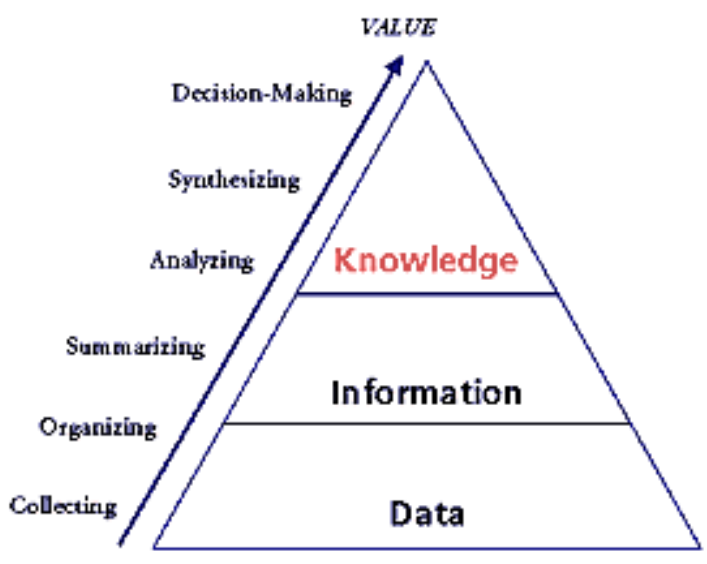

\section{Classification of Knowledge}

There are two types of knowledge common to most organizations: 


$\begin{array}{ll}\text { 1. } & \text { Explicit } \\ \text { 2. } & \text { Tacit }\end{array}$

Explicit knowledge can be expressed in words and numbers and shared in the form of data, scientific formulae, product specifications, manuals, universal principles, and so forth. Using a systematic and formal way, such knowledge can be communicated among the individuals. In the West, this form of knowledge is the most popular one. As for the people of Japan, knowledge is implicit and requires much effort to become visible. When knowledge is implicit, it cannot be easily shared with others. Such knowledge remains rather personal for the individuals and is expressive of personal deeds and experiences of the individuals.

There are two dimensions of tacit knowledge:

1. Technical - the skills or crafts commonly known as 'know-how'

2. Cognitive - consisting of beliefs, ideals and values

"Technical" dimension encompasses the kind of informal and hard-to-pin-down skills or crafts often captured in the term "know-how". Technical expertise usually comes after years of experience. Scientific and logical principles are not understood in the beginning of such experience and expertise. As for the implicit knowledge, it is through which individuals perceive the world.

"Cognitive" dimension consists of beliefs, perceptions, ideals, values, emotions and mental models so ingrained in us that we take them for granted.

Knowledge Management is a business process through which firms create and use their institutional or collective knowledge. Organizations manipulate knowledge management for solution of problems, preparation of strategic plans, decision-making, and learning.

Knowledge Management is concerned with the critical issues of organizational adoption, survival and competence in the face of environmental change. Essential segments of knowledge management include such organizational process wherein information and data received through the help of technologies are combined with the innovative and creative potentials of man to get an output bearing benefits of the both.

\section{APPROACHES TO KNOWLEDGE MANAGEMENT}

The growing attention that knowledge management is receiving has led to a proliferation of viewpoints, approaches, theoretical discursions, and practical tools and methods. To say the least, these do not converge on a clear and unambiguous notion of knowledge management. In an attempt to provide an overview, Verwijs et al. (1999) used two distinctions for sorting the various approaches:

1. The Engineering approach

2. The Management approach

According to the engineering approach, a problem can be easily solved when it is divided into segments. First, these segments of the problem are solved and then solutions of all segments are combined for a whole. A management or holistic approach stresses the need for considering the 'whole' knowledge-related situation, including the organizational context in which problems occur and become meaningful. It argues that the complexities characteristic of knowledge-related issues preclude the full understanding and control of knowledge in organizations in identifiable sub-problems. Because the management approach claims that aspects can only be fully understood as related to the context that defines them and not only as elements in themselves, it denies the validity of the thesis underlying the engineering approach; i.e. a satisfactory solution to knowledge-related problems can be attained by summing up the partial solutions.

Second, Verwijs et al. (1999) distinguished between four classes of approaches on the basis of their main focus regarding content: 
1. Knowledge storage approaches

2. Knowledge processes or knowledge flow approaches

3. Organizational learning approaches

4. Knowledge measurement or knowledge asset approaches

The knowledge storage approaches typically have an engineering focus. They concentrate on explicit knowledge dissociated from the human knowledge carrier, as tacit knowledge can only be stored after having been made explicit. Recently, these approaches have shown a growing interest in the ideas of knowledge engineering and knowledge-based systems originating from artificial intelligence research (e.g. Abecker et al., 1997; Meltsner, 1997; Van Heijst et al., 1997; Wielinga et al., 1997; Nissen 1997). The knowledge processes or knowledge flow approaches stress the dynamic character of knowledge and its dependence on human individuals ('Knowledge only exists if someone has knowledge'). They identify individual knowledge processes (knowledge acquisition, creation, distribution, etc.) and connect these in order to form knowledge chains (e.g. Weggeman, 1966; Dieng et al., 1999). Both engineering and management approaches occur in a knowledge chain or knowledge flow, depending on whether they concentrate on the individual processes or on their mutual relations. The organizational learning approaches, which have a history that is older than knowledge management history, focus on the processes of the learning of individuals in groups (Bateson, 1972; Argyris and Schon, 1978; Senge, 1990; Huber, 1992). While the discussions on organizational learning lack a generally accepted perspective (for example see Garvin, 1993), a common trait of the various approaches is that they all develop a management perspective on a central aspect of how organizations should deal with their knowledge creation. This common focus justifies treating organizational learning discussions as contributors to the knowledge management literature. The fourth class of knowledge management approaches that Verwijs et al. (1999) discerned concerns discussions as to how to measure and evaluate the intangible assets or resources of an organization. These discussions seem to converge around the notion of intellectual capital (e.g. Edvinsson and Malone, 1997; Bontis et al., 1999). The intellectual capital approach is a clear example of an engineering approach.

\section{IMPORTANCE OF KNOWLEDGE MANAGEMENT IN ORGANIZATION DEVELOPMENT}

The unprecedented escalation in the number of organizations that have decided to internationalize their operations in the last two decades, the international movement of labor that has accompanied such expansion, and the changes taking place in the world economy have increased the importance of understanding knowledge management. Hence, the need for knowledge management, or what can be called a knowledge foundation. There are four key features to this foundation:

1. A knowledge-based strategy

To push ahead into new products, markets and ways of doing business requires information and knowledge.

2. A knowledge-sharing culture

To maximize the impact of information collected and knowledge acquired, knowledge workers are being encouraged to share their best practices, new techniques, and lessons learned with their colleagues, wherever they are in the organization or around the world.

3. A technical support infrastructure

Huge investments are being made in hardware and software to ensure that the information and knowledge available within an organization is available to the people who need it and in a form that they can use. It is very much possible to manage such changes provided that costs are involved.

4. Business research and analysis

There is increasing concern that despite the flood of information available, it is often in a form that is not useful or even useable. Organizations are largely inclined to revert to such experts who bear the ability to 
interpret the information, thus assigning certain value to this information.

Thus, the success of businesses depends critically on the quality of available knowledge. It takes a firm/organization years to get knowledge from the experience of its industry or business. Such experience may be rightfully termed as the intellectual capital, extensively referred to as a critical resource.

1. Knowledge Management is important because what worked yesterday for a company may or may not work tomorrow. Knowledge Management helps sustained and in-hand methods of learning.

2. Knowledge Management systems allow the sharing of best practices from one part of an organization to another in order to create a stronger organization through cooperation.

3. Knowledge is worth more than land or property and, unlike such traditional assets, does not diminish in value.

\section{KNOWLEDGE CONVERSION AND CREATION}

In 1995, Nonaka and Takeuchi claimed that human knowledge is created and expanded through social interaction between tacit and explicit knowledge. This course of action is termed 'knowledge conversion'. Therefore, implicit and explicit forms of knowledge interact and interchange with each other in creative activities of humans.

\section{CREATING KNOWLEDGE}

The question is, "How can a company develop a system to encourage better use of its knowledge; that is, how knowledge can be created within an organization?"

One of the most fitting systems for bringing about knowledge creation within an organization is referred to by Nonaka and Takeuchi (1995) as the 'middle-up-down system'. Where common structures in organizations include the 'top-down' or hierarchical approach, in this system, knowledge is created by middle managers who are often leaders of teams. Knowledge develops through a spiral conversion process involving both the top and the front line employees, thereby putting middle managers at the center of knowledge management.

\section{ORGANIZATIONAL LEARNING AND KNOWLEDGE MANAGEMENT}

Organizational learning has become an increasingly important concept in today's business world. Fiol and Lyles defines it as "The development of insights, knowledge and associations between past actions, the effectiveness of those actions, and future action".

On the basis of this definition, it may be said that learning and knowledge management are the two important indicators that help identify the success of a company.

Knowledge is more conveniently transmitted and accessible to the workforce of an organization or company that is knowledge-oriented. Having access to organizational knowledge, individuals are able to know their environment and make it worthwhile. Performance of such workers can be improved through learning, sharing a vision and helping the organization develop in terms of strength.

\section{KNOWLEDGE MANAGEMENT IN ORGANIZATIONS}

Society, both present and future, depends on knowledge. Discovery of knowledge is an act of value creation, which is true not only for large firms, but also, in general, for any society. Knowledge is now considered an asset, which is of key importance. The degree of manipulation of this asset can determine the success of a company or organization. 
In the industrial era, mechanization and automation processes introduced considerable improvements in the efficiency and effectiveness of organizations. This way their manual labor became of value and their skills made them of worth, which ultimately helped decrease unemployment in the industrialized countries. In present times, however, knowledge workers are of greater value than those in the past having significant impact on unemployment and jobs conditions. Consequently, the number of workers in an organization has become lower.

It may be noted that there is a great tendency of competition in the present day world because consumers are now quite sophisticated. For meeting the demands of competition, companies have to be innovative in terms of costs and expansion of markets.

The organizations may therefore be said to be reforming their processes. Knowledge Management is quite familiar now in the business sector and organizations therefore have started realizing that they carry with them much potential that has still to manifest.

Besides requiring to be cost-efficient and effective in terms of management in the solution of problems, decision-making, innovation and other aspects needed to develop a competitive edge, Knowledge Management has also emerged to preserve, organize, arrange, and disseminate the expertise and also the knowledge that organizations may not be containing in an organized and well-structured form.

$\mathrm{KM}$ is the management of corporate knowledge that can improve a range of organizational performance characteristics by enabling an enterprise to be more "intelligent acting" (Wiig, 1993). It is not a new movement per $s e$, as organizations have been trying to harness their internal processes and resources that have resulted in various movements over the years as total quality management, expert systems, business processes re-engineering, the learning organization, core competencies, and strategy focus (Shukla, 1997). In well reputed organizations, when people are hired, the managers utilize the skills and knowledge of these people and manipulate it to the advantage of effective management. Several organizations have started focusing their attention on this aspect in a more organized and formal way.

Knowledge is a basic factor which, when applied successfully, assists firms and organizations to offer inventive products and services. In terms of epistemology, knowledge and knowing are respectively described as social sciences and psychology.

The term knowledge management is pretty hard to be assigned a specific definition. In fact, the corporate perspective of knowledge is very meaningful and practical. Davenport and Prusak (1998) define knowledge as "... a fluid mix of framed experience, values, contextual information, and expert insight that provides a framework for evaluating and incorporating new experiences and information ...". Dr Carla O'Dell, President of American Productivity and Quality Center, states that "Knowledge is information that has value ..." (Elliott, 1996).

Most organizations keep a vast amount of knowledge in various organizational processes, norms and practices and culture. This knowledge, however, is diffused and not generally recognized. At times, the culture of an organization itself keeps people from sharing and disseminating their knowledge and skills in an effort to retain their individual power base and viability. It is challenging to know the degree or amount of knowledge individuals possess in an organization. This very fact indicates a clear need of having a knowledge management system for organizations so they can identify and access skills and expertise of their workforce.

\section{KNOWLEDGE MANAGEMENT TRENDS}

Modern innovations in the field of telecommunications have helped new methods of knowledge management by removing/condensing the time and space limitations. These innovations have not just facilitated sharing information across an entire organization, but almost made it imperative for the continued survival and expansion of an organization. This concept is clearly supported by the emerging new organizational theories that imply that the only competitive advantage a firm has in the $21^{\text {st }}$ century is what they know and how they use it. 
There are currently two major trends in KM:

1. Measuring the intellectual capital of an organization: developing measurement ratios/indexes and benchmarks

2. Knowledge mapping: capturing knowledge gained by individual and disseminating it throughout the organization, mainly via information technology

As a discipline, knowledge management shares ideas from a number of other disciplines and faculties of knowledge. A lot of effort is being made in the field of non-natural intelligence, particularly expert systems that are capable of engineering knowledge, dispersion of knowledge, etc.

Where there are groups and teams working together, knowledge management and group support systems have common concepts of working. Also, KM and data mining are related, as they deal with knowledge creation that can be performed by identifying creative means to glean knowledge from existing data (in databases, data warehouses, text documents, etc.). The real benefit and utility of this approach is that it provides a knowledge base which serves as an instrument to fashion information in uneven locations and converting knowledge into comprehensive answers that could be consumed in the enterprise whenever needed. When knowledge in organizations can be transmitted from individual to individual, only then can the organizations guess the right value of their knowledge assets.

Based on the work of Nonaka and Takeuchi, Data Ware Technologies, in their executive briefing, identify the following four processes that are used by organizations for knowledge conversion:

1. Socialization: sharing of experiences through observation, imitation and practice. It generally takes place at seminars, workshops, conferences and similar events.

2. Capture: the conversion of tacit knowledge (e.g. what one learned at a workshop) into explicit form (e.g. written report)

3. Dissemination: the copying and distribution of the explicit knowledge

4. Internalization: process of experiencing knowledge through an explicit source; i.e. an individual can compare his/her experience of going through some workshop report with his/her past experiences.

Multinational companies are moving toward new organizational models, emphasizing on radical decentralization, coupled with advanced IT that allows organizations to tap into its intellectual assets.

$\mathrm{KM}$ is more relevant to enterprises that are operating in knowledge intensive areas. To find the organizations selling knowledge in a direct way, one can look at the consulting firms. For the purpose of creating, applying and disseminating knowledge, an organization's competency can be judged from various aspects. Demarest (1997) identified six key questions an organization has to answer to effectively participate in KM. In summary, they relate to:

1. The culture, actions and beliefs of managers about the value, purpose and role of knowledge

2. The creation, dissemination and use of knowledge within the firm

3. The kind of strategic and commercial benefits a firm can expect by the use of effective KM

4. The maturity of knowledge systems in a firm

5. How a firm should organize for KM

6. The role of information technology in the KM program

In the traditional MNC, information is considered to be the primary intangible asset. What the practices of knowledge management do, they concentrate on a centralized customization of knowledge, the obvious purpose whereof is to keep abreast of the new markets through transference of know-how. This practice is in line with the globalization approach utilized by Japanese firms since the 1960s, based on scale efficiencies, in particular the upstream value-added activities, such as product development, procurement, and manufacturing. In independent businesses, overseas operations are managed as portfolios of independent businesses. 


\section{PRACTICE OF KNOWLEDGE MANAGEMENT IN MULTINATIONAL COMPANIES}

The traditional MNC utilizes IT to capture and store relevant information about employees, customers, competitors, suppliers, and institutional and organizational regulations. This information, obtained either from the internal or the external environment, is typically stored in the form of documents or is kept as raw data in spacious database systems in data warehouses. This is also done by the use of document management applications. Those information applications provide centralized repositories of information, operational processes, expertise, or knowhow generated by individuals or groups facilitating document search and distribution of knowledge. Headquarters act as information brokers, coordinating and controlling information flow in an effort to benefit from economies of scale on information.

In MNCs (Multinational Corporations) organized as networks, knowledge is captured, codified, stored and categorized for multiple uses throughout the entire organization. For the sake of the protection of highly valuable knowledge, usually only the members of the community are allowed access to it because the multinational corporations are treating knowledge as a trade item, with external parties like distributors, suppliers and customers. As for outside community, temporary access may be granted to some parts.

Firms make use of a number of applications of IT, like business intelligence systems. The objective of such utilization is to have reason for enhancing amounts of pertinent information.

In companies referred to as e-companies, terms like innovation and using innovations are the key terms in practices of knowledge management. Here, the centre of attention is not the products, but the processes. Information and knowledge are worthwhile assets only when these are integrated with the strength to innovate. Since the customers increasingly demand well-designed business solutions covering the whole value system, the multinational companies will have to develop altogether novel markets and industries by creating the conditions to help the growth of collaborative innovation.

\section{FIVE STEPS TO KNOWLEDGE MANAGEMENT SUCCESS IN AN ORGANIZATION:}

Although all companies are different in structure and policy, five general steps can be identified and suggested in the pursuit of KM success:

1. Identify business problems and develop a clear set of goals for knowledge activities. Clear goals and objectives give corporate members a general direction regarding what kind of knowledge they ought to seek and create. Successful implementation of KM requires a clear identification of the business problem.

2. Create a 'knowledge crew'. A well-staffed team consisting of members from all levels of the organization is crucial for successful implementation of KM activities.

3. Adapt all level managers to the process. Without the support of top-level managers, the success of KM activities will be seriously affected.

4. Help companies to change their organizational culture to implement KM activities. Although culture is not the sole determinant of knowledge improvements, it has a crucial impact on all steps of the process. Training is one way of initiating change.

5. Provide access to knowledge using various networks and technologies. For KM to be open, technology plays an important part. For example, Intra and Internets, as well as brainstorming applications and so on, can be useful tools. Also, contact management software can allow users to share leads.

\section{MEASUREMENT OF KNOWLEDGE MANAGEMENT}

There is still no absolute measurement matrix in the literature to measure the success of a KM effort at an organization, though there are various measures in practice.

Apart from the quantity of copyrights, trademarks, patents, and some other aspects of knowledge can also be mentioned; for example, customer satisfaction, financial bottom line (dividends, net present value, stock prices), efficacy of processes of the business, strength to continue innovation and variations and refinements with the help of 
organizational learning, and quantifying the factors of critical gains.

Financial measurement cannot be fully carried out using traditional ways because in such methods, intellectual capital is not considered an asset. There obviously appears a need to design such accounting procedures that could value intangible assets of an organization in addition to incorporating models of intellectual capital, that in some form or method, quantify the pace of innovation and the growth of core competencies.

Knowledge needs to be used and useful in promoting the ultimate goals of the organization to be worth pursuing. At present, in spite of the widespread belief in its benefits, the specific contribution of KM to revenue is very difficult to determine and a lot of the investment in it is an act of faith (Chard, 1997).

\section{KNOWLEDGE MANAGEMENT: FUTURE AND CHALLENGES}

Information overload is a potential problem. Databases when become very large, they become difficult to navigate and slow to use, causing people to fall back on informal information-gathering or on asking contacts about which of the more formal sources of codified knowledge to use. The situation may ultimately lead to so-called "information junkyards" of barely accessed databases cluttering the knowledge management systems of the firm. This issue can be tackled by employing experts to filter and maintain the databases, but this is an expensive option and could potentially shift "ownership" of the company's knowledge base away from the employee population and into the hands of a small number of "database experts", thus defeating the whole object of KM.

Perhaps the greatest challenge in optimizing the use of knowledge management systems is in balancing the quest for knowledge against its usefulness. As one consultant, quoted in Bartlett (1998), comments, "The risk is that the more time we spend searching out the right document, the ideal framework, or the best expert, the less time we spend thinking creatively about the problem."

From company to company and organization to organization, specific approaches to knowledge management differ. However, this difference helps the emergence of common concerns and key themes. What knowledge management demands is that there should be a significant change in organizational culture and a determination by a firm at all levels to make such a change functional. A sound technological infrastructure that is designed to meet the demands of each organization makes available the tools required to ascertain the success of knowledge management endeavors. Numerous experiences of the corporate businesses reveal that for gathering more data and information, knowledge management needs no large number or better tools, but rather, it needs a new angle of vision and perspective to connect the pieces of information that encourages understanding and motivates action to create knowledge.

KM concerns itself with not just tapping into corporate memory, but also with corporate skills and existing intellectual capital. An intense pace of competition, global markets, informed customers, and technological innovations has made the marketplace an increasingly level playing field. Organizations need to harness its knowledge, not just to stay competitive, but to also become innovative. They need to not just be nimble, but "intelligent organizations".

As Nobel Laureate, Murray Gell-Mann, noted, people and computers differ in their ability to make sense of incomplete information. People can make sense (construct and interpret meaning) of fragmentary and incomplete information, but computers cannot. We learn from people as to what they are doing and what they need. If we can effectively record and disseminate peoples' knowledge, others can learn and use it. A supportive organizational climate, ideally through good KM, can bring entire organizational learning and knowledge to bear any problem, anywhere in the world, and at any time.

There is, in fact, an urgent need to develop measures for KM for a CEO to realize if KM is working for an organization, to determine what value is being added to its processes and products, and to determine what implications there are for competition by enhanced sharing and collaboration. Intelligent organizations are recognizing that knowledge, as an asset, can provide them with the ability to continuously compete and innovate into the new millennium. 


\section{MANAGERIAL IMPLICATIONS}

It is difficult to separate knowledge from the development of contemporary information and communication technologies, and many have considered technology as an important enabler in knowledge management. If applied with a well-defined purpose and in a culturally and financially sensible manner, groupware, databases, portals, intranets and other formal knowledge repositories and electronic networks can be used meaningfully for the purposes of knowledge creation and knowledge sharing between individuals within or among organizations.

These tools, if introduced and watched cautiously, have got the potential to give out strong opportunities of learning and proof of great worth. However, this fact may be kept in mind that knowledge management depends on social patterns, practices and processes to a great extent. Moreover, this KM functions much above the IT technologies and infrastructures. In the present-day multinational companies, it is hard to think of effective management without introducing suitable KM practices. Traditional MNCs seek to develop global competitive advantages through centralized economies of information, whereas networked MNCs act more as integrated learning organizations. The e-business MNC is further differentiated and seeks to reap advantages from a distributed, boundaryless system of virtual communities of practice.

The challenge faced by managers of MNCs is to ascertain that the knowledge management practices fit the respective structural configurations and communication patterns established and exercised within the company, as well as the competitive dynamics exhibited in the industry and context at large. Recognizing the importance of these dimensions as components of a system, and carefully following the dynamics in this system, is a prime challenge for management in modern MNCs. If, for instance, the structural configuration and the communication patterns pull in a direction different from the way the knowledge management system is designed and the IT applied, or if any of these elements are distant from the competitive dynamics of the industry within which the firm is embedded, the entire system is likely to collapse. An alignment of the different elements is needed to secure not merely a wellfunctioning fit, but a positive synergy of integrating the single elements into a larger system. This is the only way to turn management of knowledge as an important ingredient of sustainable competitive advantage.

\section{CONCLUSION}

It is observed that variations occurring in the world economy have turned knowledge management a necessary element for a business, particularly for sizeable multinational organizations that operate or are likely to operate internationally. The skepticism prevailing about knowledge management is not surprising. It appears to be like a temporary fashion that may not be adopted for its expense. However, as for the firms, organizations and companies that are becoming part of the global business community, quick and fast availability of information is very essential to them.

For those companies remaining local and domestic and in more traditional industrial sectors, the demand for knowledge may be of less significance. Advancements in computer technology and automation during the last decade suggest that it is not a big deal for the organizations to disseminate information to their customers, suppliers and offices across the globe with a much higher speed than before.

Businesses around the world have been greatly influenced by the emergence of the World Wide Web (www) and internet. The modern IT systems have brought in latest forms of businesses and have disseminated information widely and conveniently handy. The IT systems have also had a huge impact, particularly in the advanced economies, on the learning and skills of the workers, and it is estimated that 80 percent of all jobs around the world, especially in advanced countries, will require "head" as opposed to "hand" skills in the near future. It may be further mentioned that on account of rapid technological innovations in the field of telecommunications, organizations are doing business in changed styles. Plants, offices and people can be based almost anywhere around the world. This aspect has contributed to the doubling of world trade in the last ten years. Global economic growth has been greatly assisted by the ability to transfer funds electronically around the world, leading to massive inflows of capital into developing markets. It is notable that by virtue of global economic growth, a number of developing states have been found to be low-cost locations where high-quality products could be manufactured. Consequently, 
these states have gained much wealth and, at the same time, decreased in low-skill jobs in the richer economies.

The marketplace is becoming increasingly competitive and knowledge must evolve and be assimilated at an ever faster rate. Now organizations must be capable of planning and making analysis of their businesses with regard to their existing knowledge and the knowledge they want to have.

Therefore, a company's KM strategy should reflect its competitive strategy. Top management of an organization or firm must have the ability to assess the reason why customers are buying a company's product or service rather than those of the competition. An effective strategy of knowledge management can be designed by finding comprehensive and vivid answers to the following questions:

1. What value do customers expect from the company?

2. How can the existing knowledge of the company add value for customers?

3. What are the organizational needs for the future?

It has become a truism in management circles that knowledge and knowledge management are vital in generating sustainable competitive advantages for companies. However, as for what are the best methods to establish knowledge management within an organization, it is hard to find agreement. It is observed that businesses are consuming considerable time and money to develop KM systems; however, whether and to what extent the investment on this account will generate returns for the organization, several questions still need to be addressed.

\section{AUTHOR BIOGRAPHIES}

Professor (Meritorious) Dr. M. Abuzar Wajidi is presently Dean, Faculty of Management \& Administrative Sciences, and Director Evening Program, University of Karachi (Pakistan). With 33 years long teaching experience, he has so far produced $19 \mathrm{Ph}$.Ds, has published one book and authored articles in 40 plus national/international journals. Human Resource Management, Local Government \& Public Administration are his subjects of specialization. He is presently President (Pakistan Chapter), Association on Employment Principles \& Practices (AEPP), New York, USA. He established Public Administration Program as full-fledged department at Karachi University and also introduced HRM as subject of specialization in public universities of Pakistan.

Muhammad Asim is a faculty member at the Karachi University Business School, University of Karachi, Karachi, Pakistan. He earned an Engineering Degree from NED University of Engineering and Technology, Karachi and MBA from University of Karachi. Currently he is pursuing a $\mathrm{PhD}$ degree in Management from University of Karachi. The research interest focus on management practices in multinationals, corporate social responsibility, organizational development and change and organizational creativity. He had also served in the corporate sector for a couple of years as a design consulting engineer and contributed research papers in reputed research journals.

\section{REFERENCES}

1. Gray, P., Tehrani, S., 2002, "Technologies for disseminating knowledge", Holsapple, C.W., Handbook on Knowledge Management 1: Knowledge Directions, Springer-Verlag, Heidelberg, 109-28.

2. Grover, V., Davenport, T.H., 2001, "General perspectives on knowledge management: fostering a research agenda", Journal of Management Information Systems, 18, 1, 5-21.

3. Hammer, M., 1990, "Reengineering work: don't automate", Harvard Business Review, July, 104-12.

4. Hansen, M.T., Nohria, N., 1999, "What's your strategy for managing knowledge?", Harvard Business Review, March-April, 106-16.

5. Holsapple, C.W., 2002, "Knowledge and its attributes", Holsapple, C.W., Handbook on Knowledge Management 1: Knowledge Matters, Springer-Verlag, Heidelberg, 165-88.

6. Jackson, C., 2001, "Process to product: creating tools in knowledge management", Malhotra, Y., Knowledge Management for Business Model Innovation, Idea Group Publishing, Hershey, PA, 402-13.

7. Koenig, M.D., Srikantaiah, T.K., 2000a, "The evolution of knowledge management", Srikantaiah, K., Koenig, M.E.D., Knowledge Management for the Information Professional, Information Today Inc., Medford, NJ, 37-61. 
8. $\quad$ Kraemer, K., 2001, "The productivity paradox: is it resolved? Is there a new one? What does it all mean for managers?", working paper, Center for Research on Information Technology and Organizations, UC Irvine, Irvine, CA.

9. Malhotra, Y., 1997, "Knowledge management in inquiring organizations", Proceedings of 3rd Americas Conference on Information Systems (Philosophy of Information Systems Mini-track), Indianapolis, IN, August 15-17, 293-5.

10. Malhotra, Y., 1998b, "Knowledge management for the new world of business", Journal for Quality \& Participation, 21, 4, 58-60.

11. Malhotra, Y., Galletta, D.F., 1999, "Extending the technology acceptance model to account for social influence: theoretical bases and empirical validation", proceedings of the Hawaii International Conference on System Sciences (HICSS 32), 6-19.

12. Malhotra, Y., Galletta, D.F., 1999, "Extending the technology acceptance model to account for social influence: theoretical bases and empirical validation", proceedings of the Hawaii International Conference on System Sciences (HICSS 32), 6-19.

13. Nonaka, I., Takeuchi, H., 1995, The Knowledge-Creating Company, Oxford University Press, New York, NY.

14. O'Leary, D., 2002, "Technologies of knowledge storage and assimilation", Holsapple, C.W., Handbook on Knowledge Management 1: Knowledge Directions, Springer-Verlag, Heidelberg, 29-46.

15. Porter, M.E., Millar, V.E., 1985, "How information technology gives you competitive advantage", Harvard Business Review, 63, 4, 149-60.

16. Susarla, A., Liu, D., Whinston, A.B., 2002, "Peer-to-peer knowledge management", Holsapple, C.W., Handbook on Knowledge Management 1: Knowledge Directions, Springer-Verlag, Heidelberg, 129-40.

17. Nonaka, I. and Takeushi, H. (1995), The Knowledge-Creating Company, New York: Oxford University Press. 